\title{
Setting a standard for tailings dam management
}

\author{
D. Brett GHD Pty Ltd, Australia \\ B. Brown Rio Tinto Technology and Innovation, Australia
}

\begin{abstract}
The Australian National Committee on Large Dams (ANCOLD), is an incorporated voluntary association of organisations and individual professionals with an interest in dams in Australia. ANCOLD was formed in 1937 as the Australian national committee of the International Commission on Large Dams (ICOLD), a nongovernment organisation established in 1928, and is one of 81 member countries. ANCOLD has been instrumental in establishing a high standard of management of dams in Australia.

ANCOLD sees the need to assist the mining industry and the community by providing technical advice on appropriate standards for tailings management and to provide a forum for the support of technical development of these structures. As part of this strategy, ANCOLD has established a sub-committee including leading practitioners from consulting, mining academic and regulator backgrounds to review their 1999 Guideline on Tailings Dam Design, Construction and Operation. The scope of the new guidelines has been extended to provide particular guidance on the use of risk assessment techniques to assist decision making in various aspects of tailings dam management and to provide guidance on design issues related to dam closure and post closure performance. These include issues such as consequence assessment, freeboard requirements, seepage control, earthquake design methods and recommended factors of safety, with particular attention to the potential significant difference between tailings dams and conventional water dams.
\end{abstract}

This paper presents preliminary information on progress on the draft guidelines. A final draft document is scheduled for presentation at a tailings specific workshop as part of ANCOLD's annual conference in November 2010, this will be issued for industry comment in early 2011, with release expected later in the year.

Input into the guidelines is sought from persons involved in all aspects of tailings management, particularly from mining companies and regulators, for whom these ANCOLD guidelines may become an important part of operations over the next decade.

\section{Introduction}

This paper describes the status of a new Australian National Committee on Large Dams (ANCOLD) publication 'Guidelines on Planning, Design, Construction, Operation and Closure of Tailings Dams' currently being prepared for release in 2011. This guideline will supersede the current 'Guideline on Tailings Dam Design, Construction and Operation' (ANCOLD, 1999).

ANCOLD is an incorporated voluntary association of organisations and individual professionals with an interest in dams in Australia, including many mining companies and professionals working in the mining industry. ANCOLD was formed in 1937 as the Australian national committee of the International Commission on Large Dams (ICOLD), a non-government organisation established in 1928, and is one of 81 member countries. ANCOLD has been instrumental in establishing a high standard of management for dams in Australia.

\section{ANCOLD sub-committee}

ANCOLD have established a sub-committee including leading practitioners from consulting, mining academic and regulator backgrounds comprising the members listed in Table 1. 
Table 1 ANCOLD tailings guideline sub-committee

\begin{tabular}{ll}
\hline $\begin{array}{l}\text { David Brett (Convener) } \\
\text { Imran Gillani }\end{array}$ & $\begin{array}{l}\text { GHD Pty Ltd } \\
\text { URS Australia Pty Ltd } \\
\text { Keith Seddon }\end{array}$ \\
Norm Himsley & $\begin{array}{l}\text { ATC Williams } \\
\text { Consultant, formerly NSW Dam Safety } \\
\text { Committee }\end{array}$ \\
Russ McConnell & $\begin{array}{l}\text { Department of Environment, Resources and } \\
\text { Minerals Queensland }\end{array}$ \\
Dr Gary Bentel & $\begin{array}{l}\text { Consultant (ex BHP Billiton) } \\
\text { Dr Bruce Brown }\end{array}$ \\
Prof. Andy Fourie & $\begin{array}{l}\text { The University of Western Australia } \\
\text { Prof. David Williams }\end{array}$ \\
Reviewers & The University of Queensland \\
John Phillips & GHD Pty Ltd \\
Yet to be confirmed & International \\
\hline
\end{tabular}

\section{Scope}

The revised guideline was seen as necessary, to not only review the general technical content of ANCOLD's 1999 document but specifically, to highlight the consideration of risk through all aspects of the tailings dam life cycle and also to extend the advice on designing for the closure and post-closure phases. The guideline is intended to support existing guidelines such as 'Tailings Management' one of a series of publications under the Leading Practice Sustainable Development Program for the Mining Industry published by the Australian Government Department of Industry, Tourism and Resources (DITR, 2007). It is intended that the ANCOLD guidelines provide additional advice to designers intending to achieve sustainable development as defined by the International Council on Mining and Metals (ICMM, 2003) as being, "technically appropriate, environmentally sound, financially profitable and socially responsible".

The guideline also introduces the concept of design evolution, whereby initial design must adopt conservative design parameters that can be progressively refined by observation and monitoring as the real data on the tailings and storage performance becomes available.

The guideline is primarily directed at providing advice on the above ground storage of tailings but many of the principles apply to other forms of tailings management.

\section{Purpose of the guideline}

Tailings dams have many similarities to conventional water holding dams. However, ANCOLD considers that there are sufficient important differences to justify preparation and now updating, of a specific guideline for tailings dams. This will continue to provide a coherent and thorough technical basis for design, operation and closure of tailings dams for the mining/minerals processing industry.

Tailings dams comprise structures to aid the storing of unwanted waste from a mineral or manufacturing process. This gives rise to the following particular features that differ from conventional dams:

- The embankments must store solids deposited as slurry as well as manage free water.

- The operating life may be relatively short but they are potentially required to safely store the tailings for extremely long periods of time, possibly 'in perpetuity'.

- They are often built in stages over a number of years. 
- The construction, particularly any subsequent raising, sometimes may be undertaken by mine personnel without the level of civil engineering input or control applied to conventional water dams.

- The materials, both those used for embankment construction and the tailings themselves, are likely to vary during mine life.

- Water management is crucial, particularly if harmful materials are contained, and because of its potential to influence stability.

- Seepage and dust may have a major impact on the environment.

- Daily operations such as placement of tailings and recovery of water are critical to the safety of the storage.

- The filling rate, the ultimate height and even the overall storage configuration may well change in unforeseeable ways during construction and operation.

- The storage must be designed with mine closure in mind, so as to create a permanent, maintenance free deposit that does not pose any unacceptable environmental impact or risk.

To highlight these differences, the term tailings storage facility (TSF) is often used, instead of dam. In some cases, tailings storage can be successfully achieved with minimal requirement for embankment dams in the traditional sense.

The primary objectives for the design of a TSF are:

- the safe and stable containment of tailings

- the safe management of decant and rainfall runoff

- the management of seepage

- to allow long-term effective closure, leaving no unacceptable environmental legacy

- to achieve these objectives in a cost effective manner.

Whilst the guidelines are intended to be specific to the embankments related to tailings storage, the issues inevitably require consideration of waste disposal strategies, operational procedures and decommissioning.

\section{$5 \quad$ Key management considerations}

\subsection{General}

Key management considerations required for a tailings dam are:

- a selection of appropriate tailings management system

- risk-based design and management

- life of mine planning

- an observational approach - managing uncertainty.

These are discussed briefly to indicate the approach of the forthcoming guidelines.

\subsection{Waste containment principles}

Key features that need to be considered include:

- Tailings dams should normally be used primarily for the containment of tailings. The amount of water stored on a tailings storage should be minimised to encourage drying and consolidation of the tailings except where specific design requirements dictate otherwise, such as sub-aqueous containment for prevention of oxidation or other chemical reaction. In such cases, consideration needs be given to the potential lower density of tailings and the increased risk of seepage or overtopping. 
- The need for suitable lining or underdrainage to minimise or manage seepage should be assessed at the initial planning stage based on thorough hydrogeological studies, chemical analysis of leachate toxicity and impact studies. The long-term performance of liners will need to be taken into account.

- Thick deposits of wet slimes should be avoided. They commonly result in poorly consolidated and weak tailings, which require greater storage volume and are difficult to cap and rehabilitate in the long term.

- Deposition of coarse tailings against embankment walls is to be encouraged for sub-aerial containment where upstream lifting is proposed, to ensure rapid consolidation, drying and gain in strength.

- Tailings may be stored to a level higher than the crest of the tailings dam wall (e.g. dry stacking) provided that such heaped tailings can be demonstrated to be geotechnically stable under all conditions including earthquakes.

- Deposition procedures or landforms that facilitate excessive dust creation, leaching of tailings and leachate transport should be avoided.

- The storage facility should be designed having regard to the potential for adverse chemical reactions within the tailings mass, foundations, and storage structures.

- All storages must be designed with adequate freeboard to retain suitable design floods, both during operation and post closure, with spillways, if necessary, to pass higher floods without damaging the dam or retaining structures..

- All earth-fill structures must be designed according to current geotechnical principles including appropriate seepage control, stability, internal erosion (piping) and external erosion.

- Upstream construction should only be considered on tailings that can be shown to be stable under seismic conditions applicable at the site, including potential for liquefaction of tailings under earthquake loading.

- All tailings storages must be monitored to enable performance to be compared with design assumptions and the structures then modified as necessary.

- Staged construction should be used where practical to minimise initial capital cost and to enable changes to performance and/or process operations and/or production to be accommodated in future stages.

- The design must take into account the requirements for long-term closure, which may include the expectation of producing a long-term stable landform with no ongoing maintenance beyond that for natural landforms. Prime considerations are external slopes with respect to minimising the risk of surface and internal erosion (piping), maintaining vegetation, and control of water, chemical retention and settlement of low-density tailings.

\subsection{Containment strategies}

The first step in applying these principles is the selection of a suitable containment strategy and the development of a tailings management plan. A tailings containment strategy will describe the selected method of transporting, discharging, storing, permanent retention and rehabilitation of tailings waste products for any given mineral processing plant.

A containment strategy must be selected to suit the type of process, the tailings characteristics, the nature of the available containment area, the local climate, long term requirements including capping, environmental impacts and any Statutory requirements.

Disposal strategies need to consider both the method of containment and the method of deposition. 


\subsection{Risk-based design and management approach}

Major tailings dam failures may be relatively infrequent, but the consequential harm can be enormous. Past failures have led to loss of life, catastrophic environmental damage, public outrage, restrictive regulatory intervention and associated financial losses and costs for the company responsible. There are significant measurable financial, reputation and sustainability benefits associated with leading practice tailings management that effectively manages the potential risks associated with tailings storage facilities during and after their operating lives.

Dam designers tend to focus on the design of the specific structural components and associated appurtenances (e.g. spillways, drains). However, irrespective of the detail and quality of the design, failures can occur if each tailings facility element and the system as a whole, are not designed, constructed and operated in accordance with the primary intent of controlling and managing risk.

Leading tailings management practice recognises potential design limitations and uncertainties by applying a risk-based management approach throughout the life of the facility, from project conception, through design, construction, operation and closure.

To minimise, manage and control key risks, this process starts in the project conception stage with the application of the waste management hierarchy that attempts to eliminate or reduce the quantity and improve the quality of the waste.

The risk-based process proceeds with the consideration of alternative storage methodologies such as in-pit disposal or co-location of tailings within waste dumps. Where applicable, these techniques can reduce the complexity of the containment structures and their failure likelihood and consequence.

The risk-based process then continues into the operational phase with management plans that track performance against design predictions, monitor leading indicators of failure, trigger design and operating improvements if required, and ensure quick and effective response to signs of distress or impending failure, through a site specific Dam Safety Emergency Plan.

AS/NZS ISO 31000:2009 (2009) Risk Management - Principles and Guidelines, provides a generic guide to managing risk and the key elements of the risk management process. This involves applying a logical and systematic method of establishing the context, identifying, analysing, evaluating, treating, monitoring and communicating risks in a way that will minimise losses, maximise gains, enable informed decision-making and facilitate continuous improvement in design and performance.

Within this process, risk assessment is used in varying forms to evaluate specific risk issues or a combination of risk events. The type of assessment chosen depends on the complexity of the risk, the criticality of the element under consideration (in so much as its failure may lead to safety, health, environmental, business continuity consequences), the potential consequence of a failure, and the quantity and quality of available data. The assessment of the consequences of failure leads to the establishment of design criteria and loading conditions. ANCOLD are currently also reviewing the guidelines on the Consequences of Failure to eliminate a current anomaly that fails to distinguish between tailings dams and water dams in the consequence category determination. A new category of extreme environmental consequence is being introduced that will tend to raise the consequence category of a tailings dam over a water dam of otherwise similar conditions. This means that recommended design parameters may be higher than currently used. For example, a tailings dam that would cause extreme environmental impact on failure may be classified as high consequence category rather than significant consequence category if there is no population at risk from the failure. This means that design cases may need to be elevated to probable maximum floods (PMF) and a conservative maximum design earthquake (MDE) which is appropriate for structures intended for extreme design life. In addition, the ALARP principal that risk should be as low as reasonably practical is particularly relevant when considering low probability, high consequence events. This principal proposes that where risks can be lowered even further than the minimum desirable level at relatively low cost and with low impact on other issues, then they should be.

There are likely to be significantly different consequences for some failure modes, depending on the life cycle stage of the dam. For example, erosion would be readily repaired during operation but could become a potential mechanism for large-scale failure post-closure when limited, if any maintenance is likely. 
Similarly, seepage of contaminated water can be readily collected and treated during operation but lead to significant environmental impact following closure. The impact of large-scale failure of a TSF could increase significantly with time as the structure increases in scale. Consequently, any consequence assessment needs to be undertaken for the different phases of dam life.

If a tailings dam is closed with the expectation of effective 'abandonment', particularly if the mining lease is to be relinquished, it will need to be left in a condition such that it is able to remain physically and geochemically stable and environmentally benign without the need for significant ongoing maintenance other than that expected from a similar land use. This should be tested by an appropriate risk assessment with identified risks being mitigated by design to appropriately low levels.

Where tailings dams are dewatered they may be considered not to fall under the definition of a 'dam' if the contents can be demonstrated not to pose a risk of liquefaction or subject to major erosion and release during any potential event during the long post-closure life expectation. However, ANCOLD consider that the methods outlined in this guideline would still apply, albeit that the risks of failure might be reduced.

Where a tailings dam is to be left with a full or partial water cover the storage facility should be considered to be a dam and should meet the relevant ANCOLD guidelines for ongoing performance. In this case, the requirements for surveillance and monitoring could be relaxed if the design features can be demonstrated to reduce the risks of failure to very low levels. This could be achieved by methods such as (Brett et al., 2008):

- very conservative freeboard and spillway provisions

- very conservative embankment batter slopes using stable non-erosive materials, such as waste rock

- very flat internal hydraulic gradients to minimise piping potential.

Qualitative or semi-quantitative assessments are often used to rank and prioritise risk controls and risk action plans, or to demonstrate the risk associated with a combination of events (e.g. fault event tree).

Quantitative risk assessment is frequently used by designers of high hazard dams to quantify and evaluate the risk tolerability of specific elements or features of a dam such as spillway capacity (ANCOLD, 2003).

In focussing primarily on those issues that are material to achieving the performance objectives, the riskbased approach also becomes a robust and effective management tool. Activation of this approach at the start of the project provides the dam owner with greater confidence in the design and provides the designer with the ability to tailor the design towards the owner's desired risk profile. Beneficial risk treatments may include:

- avoiding the risk by deciding not to start or continue with the activity that gives rise to the risk (where this is practicable)

- eliminating the risk (or specific hazards) through design

- reducing the likelihood of the negative outcomes, e.g. through stringent construction quality control, and through implementation of an effective surveillance and response plan

- reducing the extent and/or severity of the consequential impacts. This includes preventative measures such as increasing freeboard capacity or post-event mitigation through emergency response plans

- sharing the risk (win-win) such as backfilling a neighbour's mine void.

Risks that are retained as tolerable clearly require the effective implementation of risk controls to maintain their tolerability. Risk management encompasses the regular assessment of the facility performance against its design, during which the likelihood and consequence of hazards are rigorously reassessed, and actions are clearly defined and prioritised to minimise the occurrence or impact of the risks.

The facility risk assessment should clearly identify the leading indicators of potential failures, either of individual elements, or in combination where a number of seemingly innocent individual issues combine to result in a failure. It is useful to categorise or group leading indicators (for operations and for closure) within operational activities that require similar control measures. This will provide the owner with a greater 
appreciation of the potential weaknesses in the facility/system, allowing operational plans to be tailored to ensure that the issues identified are correctly and effectively managed.

As tailings storage facilities and the loads applied to them are constantly changing as they store more tailings, risk-based tailings management and planning must also manage these changing circumstances effectively. Several failures or near misses can be attributed to the simple misunderstanding of correct raise scheduling by an owner/operator who does not understand seasonal freeboard requirements. Managing such change should be a core consideration in the planning, design, construction, closure and rehabilitation of tailings storage facilities.

\subsection{Life of mine planning}

\subsubsection{Introduction}

It is important to consider all phases of a tailings dam's life cycle at the planning stage to ensure optimum performance. This should include:

- Development of a robust closure plan taking into account the potential final landform, land use and environmental protection systems relevant to the tailings properties and the potential for post-closure environmental impact.

- Consideration of potential changes in the tailings volume to be stored through either early closure or extended mine life due to increases in reserves.

A tailings management plan is required for the complete life of the project including closure and any postclosure care and maintenance and should form part of the Operation Management and Surveillance Manual. The plan should address design, construction, operation, closure and rehabilitation.

The plan should account for any staged development. For example, lead times for design and construction of new storages should be clearly identified relative to the estimated time of filling of existing storages. Without this, there is a risk of breaching License to Operate conditions, dams overtopping or a forced plant closure if replacement storages are not commissioned on time.

Since changes commonly occur throughout the life of a project, which can affect the operation of the tailings area, the plan should be flexible and capable of modification.

The basic steps towards preparing a tailings management plan should include the following.

\subsubsection{Design planning}

The design will evolve over several phases from concept, through preliminary design associated with a feasibility study to final design for construction. This will include the following steps, often being refined as the design progresses:

- Carry out broad topographic and local land use survey of the project area and assess the compatibility of the tailings disposal and storage options.

- Define the physical and chemical nature of the tailings and amount to be stored.

- Determine the tailings characteristics such as beaching angle, settled density, and strength by using laboratory tests or pilot trials.

- Determine if any special health and safety, handling and containment methods are required, including statutory requirements and approval processes.

- Determine tailings disposal method, rate(s) and period.

- Determine volume of liquids to be reclaimed and likely variability.

- Assess the local meteorology (wind, rain, evaporation) and seismicity of the area.

- Develop and analyse a water balance model for the proposed tailings storage area.

- Determine freeboard, overflow, and storage requirements and restrictions. 
- Estimate rate and quality of seepage losses.

- By iteration, develop a concept storage requirement and short list the suitable sites within the project area that meet the requirement.

- Carry out preliminary site investigations to assess foundation and groundwater conditions and sources of construction materials.

- Select final disposal area(s).

- Assess rehabilitation requirements. Select a storage design that best fits these requirements and allows for progressive rehabilitation.

- Carry out final design and develop a construction plan.

- Install initial site monitoring equipment.

\subsubsection{Construction planning}

A construction plan, by the designer, is required to list the order in which the various elements of the tailings storage are assembled and how the various items of work interrelate. In addition, long-term construction planning identifies latest dates by which new works must be commissioned. Typical elements would be:

- internal and external approvals

- preparation of tender documentation

- contract tender period, award and mobilisation

- foundation preparation

- construction of earthworks and/or embankment

- construction of tailings discharge system (pipework, outlets, controls)

- construction of reclaim and overflow systems

- installation of monitoring and security systems.

\subsubsection{Operation planning}

Long, medium and short-term management plans should be prepared to ensure:

- efficient filling of the disposal area

- transfer and reclaim of any decant liquors

- safe containment or control of flood waters

- periodic raising of embankments

- $\quad$ surveillance and maintenance

- progressive rehabilitation where possible

- accommodation of any variations from initial planning criteria.

\subsubsection{Integrated mine planning}

Planning should take account of the potential activities that will take place through the total life of the structure. This will include the initial 'mine life' but also consider potential extension of mining or changes in tailings properties that might affect the design.

Planning for tailings storage should take account of impacts or synergies with all aspects of the mine operation. This can be particularly important to take advantage of other mine wastes for construction, water management impacts on mining and processing and particularly on closure methodology. Often cost and environmental benefits can be made for the overall project with minor extra effort or cost impost on one 
aspect. Optimal tailings storage considerations are often not considered as part of mine or processing operations.

An example of this could be the inclusion of strategic waste rock placement at a small cost premium during operations to facilitate major cost savings at closure.

Planning should ensure that the tailings disposal area is left in such a way that it is able to remain:

- with acceptable impact on the environment

- structurally stable

- resistant to erosion

- compatible with the surrounding landform

- functionally compatible with the agreed post mining land use.

The above criteria should apply over the perceived time frame of the post-closure period, which may be indefinite. If there is no defined post-closure design life, ANCOLD, in the new guideline, recommend adopting 1,000 years as a reasonable period to adopt as being considered 'in perpetuity'.

\subsection{Evolution of design - observational approach}

Unlike water retention dams which change little subsequent to construction, tailings impoundments take many years to construct and will experience many changes which may require operational response. During the design phase, geotechnical predictions have to be made many years into the future, based on limited knowledge and key assumptions. It is essential to track these predictions, verify these assumptions, and then refine them as actual data is acquired over time. Opportunity to verify the design assumptions and to optimise/update the design, if needed, during construction is in essence what the observational approach is all about.

Central to the concept of observational approach is a sound and meaningful instrumentation and monitoring program to monitor and record key parameters affected by the changing construction and operating conditions. The observed values are compared against the design predictions to evaluate if any changes in operation or design are needed. Weekly or monthly instrumentation data reviews are very helpful in identifying any imminent problems. However, more subtle behaviours that may not be of immediate concern, but could potentially develop into serious concerns for future stages of construction, may go unnoticed during these reviews. It is essential to react to these concerns well before they become a serious problem. A modification/remediation effort could be staged over several years to minimise its impact on the overall operation. Addressing a major problem at a later stage may be operationally difficult, expensive, and could even be impractical. The observational method provides the ability to address concerns through 'prevention' rather than 'cure'.

Among its various applications, an area where the observational approach has proved to be of immense value is in the prediction of pore water pressure conditions. Even with the sophisticated numerical modelling tools that are currently available, it is unrealistic to expect that the pore pressure conditions within a TSF could be accurately predicted throughout its operational life. During TSF operations, it is very common that conditions (depositional, mineralogical, process, weather) change, leading to changes in the pore pressure conditions within the impoundment. The observational method provides the solution to rationally address this uncertainty. The design could be based on the best-estimated conditions and during operations the validity of the design pore pressure conditions would be checked and appropriate measures could be taken, if and when warranted.

Another benefit of the observational approach is that it can reduce the upfront capital cost of a project. Designing an embankment upfront to cover all eventualities, that may or may not happen, would excessively increase the project cost. In comparison, if the design is based on best estimate conditions and the observational approach is utilised, then the overall project cost, including the initial capital cost, could be significantly reduced. The best estimate design is checked against worst conceivable conditions to identify potential upgrade measures that are compatible with the proposed design. Following start-up, the observational approach is used to decide if and when these upgrade measures need to be constructed. This 
kind of proactive and vigilant involvement with the design during operations not only leads to cost savings but also reduces the overall project risk by pre-empting unanticipated problems.

\section{Conclusion}

This paper has presented preliminary information on progress on the draft guidelines and an overview of the design and management philosophy contained in them. A final draft document is scheduled for presentation at a tailings-specific workshop as part of ANCOLD's annual conference in November 2010; this will be issued for industry comment in early 2011, with release expected later in the year.

Input into the guidelines is sought from persons involved in all aspects of tailings management, particularly from mining companies and regulators, for whom these ANCOLD guidelines may become an important part of operations over the next decade.

\section{References}

AS/NZS ISO 31000:2009 (2009) Risk management - Principles and Guidelines.

Australian National Committee on Large Dams (ANCOLD) (2003) Guidelines on Risk Assessment, October.

Australian National Committee on Large Dams (ANCOLD) (1999) Guideline on Tailings Dam Design, Construction and Operation, October.

Brett, D., Hanslow, B. and Longey, R. (2008) When Is a Dam Not a Dam?, ANCOLD Conference on Dams and water for the future, Queensland, November.

Department of Industry, Tourism and Resources (DITR) (2007) Tailings Management, Leading Practice Sustainable Development Program for the Mining Industry, February.

International Council on Mining and Metals (ICMM) (2003) Sustainable Development Framework - Final Principles, Document Ref: C 020/290503, May. 